\title{
Approximate Quadratic-Additive Mappings in Fuzzy Normed Spaces
}

\author{
Ick-Soon Chang ${ }^{1}$ and Yang-Hi Lee ${ }^{2}$ \\ ${ }^{1}$ Department of Mathematics, Chungnam National University, 79 Daehangno, Yuseong-gu, Daejeon 305-764, Republic of Korea \\ ${ }^{2}$ Department of Mathematics Education, Gongju National University of Education, Gongju 314-711, Republic of Korea \\ Correspondence should be addressed to Ick-Soon Chang; ischang@cnu.ac.kr
}

Received 11 March 2014; Revised 9 May 2014; Accepted 16 May 2014; Published 26 May 2014

Academic Editor: Dorian Popa

Copyright (C) 2014 I.-S. Chang and Y.-H. Lee. This is an open access article distributed under the Creative Commons Attribution License, which permits unrestricted use, distribution, and reproduction in any medium, provided the original work is properly cited.

We examine the generalized Hyers-Ulam stability of the following functional equation: $2 f(x+y+z+w)+f(-x-y+z+w)+$ $f(-x+y-z+w)+f(-x+y+z-w)+f(x-y-z+w)+f(x-y+z-w)+f(x+y-z-w)-5 f(x)-3 f(-x)-5 f(y)-$ $3 f(-y)-5 f(z)-3 f(-z)-5 f(w)-3 f(-w)=0$, in the fuzzy normed spaces with the fixed point method.

\section{Introduction}

The problem of stability for functional equations originated from questions of Ulam [1] concerning the stability of group homomorphisms. Hyers [2] had answered affirmatively the question of Ulam for Banach spaces. The theorem of Hyers was generalized by Aoki [3] for additive mappings and by Rassias [4] for linear mappings by considering an unbounded Cauchy difference. Thereafter, many interesting results of the generalized Hyers-Ulam stability to a number of functional equations and mappings have been investigated. Especially, Cădariu and Radu [5] observed that the existence of the solution for a functional equation and the estimation of the difference with the given mapping can be obtained from the fixed point alternative. This method is called a fixed point method. Also, they $[6,7]$ applied this method to prove the stability theorems of the additive functional equation.

Katsaras [8] defined a fuzzy norm on a linear space to construct a fuzzy structure on the space. Since then, some mathematicians have introduced several types of fuzzy norm in different points of view. In particular, Bag and Samanta, following Cheng and Mordeson, gave an idea of a fuzzy norm in such a manner that the corresponding fuzzy metric is of Kramosil and Michálek type [9-11]. In 2008, Mirmostafaee and Moslehian $[12,13]$ obtained a fuzzy stability for the additive functional equation and for the quadratic functional equation.
On the other hand, there are some papers where several results of stability for different functional equations are proved in probabilistic metric and random normed spaces (see, e.g., [14-17]); after that the results were established in fuzzy normed spaces or in non-Archimedean fuzzy normed spaces [18-21]. In these papers except [20], the fixed point method is used. Moreover, in some of them another type of metric is used (see, e.g., [17]).

In this paper, we take into account the generalized Hyers-Ulam stability of the following quadratic-additive type functional equation:

$$
\begin{aligned}
2 f( & +y+z+w)+f(-x-y+z+w) \\
& +f(-x+y-z+w)+f(-x+y+z-w) \\
& +f(x-y-z+w)+f(x-y+z-w) \\
& +f(x+y-z-w)-5 f(x)-3 f(-x) \\
& -5 f(y)-3 f(-y)-5 f(z) \\
& -3 f(-z)-5 f(w)-3 f(-w)=0,
\end{aligned}
$$

in the fuzzy normed spaces via the fixed point method. First of all, it is known that if a mapping $f$ satisfies the functional equation (1), then $f$ is quadratic-additive mapping in [22]. 
Thus the functional equation (1) may be called the quadraticadditive type functional equation and the general solution of functional equation (1) may be called the quadratic-additive mapping. However, the stability problem for the functional equation (1.1) in [22] is not investigated and so in this paper we deal with the stability of this equation.

\section{Preliminaries}

We first introduce one of the fundamental results of the fixed point theory. For the proof, we refer to [23] or [24].

Theorem 1 (the fixed point alternative). Assume that $(X, d)$ is a complete generalized metric space and $\Lambda: X \rightarrow X$ is a strict contraction with the Lipschitz constant $L<1$. If there exists a nonnegative integer $n_{0}$ such that $d\left(\Lambda^{n_{0}+1} x, \Lambda^{n_{0}} x\right)<\infty$ for some $x \in X$, then the following statements are true.

$\left(F_{1}\right)$ The sequence $\left\{\Lambda^{n} x\right\}$ converges to a fixed point $x^{*}$ of $\Lambda$.

$\left(F_{2}\right) x^{*}$ is the unique fixed point of $\Lambda$ in $X^{*}=\{y \in X \mid$ $\left.d\left(\Lambda^{n_{0}} x, y\right)<\infty\right\}$.

$\left(F_{3}\right)$ If $y \in X^{*}$, then

$$
d\left(y, x^{*}\right) \leq \frac{1}{1-L} d(\Lambda y, y)
$$

We now introduce the definition of fuzzy normed spaces to establish a reasonable fuzzy stability for the quadratic and additive functional equation (1) in the fuzzy normed spaces (cf. [9]).

Definition 2. Let $X$ be a real linear space. A function $N: X \times$ $\mathbb{R} \rightarrow[0,1]$ is said to be a fuzzy norm on $X$ if the following conditions are true:

$\left(N_{1}\right) N(x, t)=0$ for all $x \in X$ and $t \leq 0$;

$\left(N_{2}\right) x=0$ if and only if $N(x, t)=1$ for all $t>0$;

$\left(N_{3}\right) N(c x, t)=N(x, t /|c|)$ for all $x \in X$ and $c, t \in \mathbb{R}$ with $c \neq 0$

$\left(N_{4}\right) N(x+y, s+t) \geq \min \{N(x, s), N(y, t)\}$ for all $x, y \in X$ and $s, t \in \mathbb{R}$;

$\left(N_{5}\right) N(x, \cdot)$ is a nondecreasing function on $\mathbb{R}$ and $\lim _{t \rightarrow \infty} N(x, t)=1$ for all $x \in X$.

The pair $(X, N)$ is called a fuzzy normed space. Let $(X, N)$ be a fuzzy normed space. A sequence $\left\{x_{n}\right\}$ in $X$ is said to be convergent if there exists an $x \in X$ such that $\lim _{n \rightarrow \infty} N\left(x_{n}-\right.$ $x, t)=1$ for all $t>0$. In this case, $x$ is called the limit of the sequence $\left\{x_{n}\right\}$ and we write $N$ - $\lim _{n \rightarrow \infty} x_{n}=x$. A sequence $\left\{x_{n}\right\}$ in $X$ is called Cauchy if, for each $\varepsilon>0$ and each $t>0$, there exists an $n_{0} \in \mathbb{N}$ such that $N\left(x_{n+p}-x_{n}, t\right)>1-\varepsilon$ for all $n \geq n_{0}$ and all $p \in \mathbb{N}$. It is known that every convergent sequence in a fuzzy normed space is Cauchy. If every Cauchy sequence in $X$ converges in $X$, then the fuzzy norm is said to be complete and the fuzzy normed space is called a fuzzy Banach space.

In this paper, we note that the triangular norm $T=\min$ is used (see the definition of the fuzzy norm, in the axiom
$\left(N_{4}\right)$ ), while in some recent papers properties of generalized Hyers-Ulam stability by taking other triangular norms have been discussed (e.g., of Hadžić type, in [25] ).

\section{Generalized Hyers-Ulam Stability of (1)}

Let $(X, N)$ and $\left(Y, N^{\prime}\right)$ be a fuzzy normed space and a fuzzy Banach space, respectively. For a given mapping $f: X \rightarrow Y$, we use the abbreviation

$$
\begin{aligned}
D f(x, y, z, w):= & 2 f(x+y+z+w)+f(-x-y+z+w) \\
& +f(-x+y-z+w) \\
& +f(-x+y+z-w) \\
& +f(x-y-z+w)+f(x-y+z-w) \\
& +f(x+y-z-w)-5 f(x)-3 f(-x) \\
& -5 f(y)-3 f(-y)-5 f(z) \\
& -3 f(-z)-5 f(w)-3 f(-w)
\end{aligned}
$$

for all $x, y, z, w \in X$.

In the following theorem, we investigate the stability problems of the functional equation (1) between fuzzy normed spaces.

Theorem 3. Let $(X, N)$ and $\left(Z, N^{\prime \prime}\right)$ be fuzzy normed spaces and let $\left(Y, N^{\prime}\right)$ be a fuzzy Banach space. Assume that a mapping $\varphi: X^{4} \rightarrow Z$ satisfies one of the following conditions:

(i) $N^{\prime \prime}(\alpha \varphi(x, y, z, w), t) \leq N^{\prime \prime}(\varphi(2 x, 2 y, 2 z, 2 w), t) \leq$ $N^{\prime \prime}(\alpha \varphi(x, y, z, w), t)$ for some $1 \leq \alpha^{\prime} \leq \alpha<2$;

(ii) $N^{\prime \prime}(\alpha \varphi(x, y, z, w), t) \leq N^{\prime \prime}(\varphi(2 x, 2 y, 2 z, 2 w), t)$ for some $0<\alpha<1$;

(iii) $N^{\prime \prime}(\varphi(2 x, 2 y, 2 z, 2 w), t) \leq N^{\prime \prime}(\alpha \varphi(x, y, z, w), t)$ for some $\alpha>4$

for all $x, y, z, w \in X$ and $t>0$. If a mapping $f: X \rightarrow Y$ with $f(0)=0$ satisfies

$$
N^{\prime}(D f(x, y, z, w), t) \geq N^{\prime \prime}(\varphi(x, y, z, w), t)
$$

for all $x, y, z, w \in X$ and $t>0$, then there exists a unique quadratic-additive mapping $F: X \rightarrow Y$ such that

$$
\begin{aligned}
N^{\prime} & (F(x)-f(x), t) \\
& \geq \begin{cases}M(x, 2(2-\alpha) t) & \text { if } \varphi \text { satisfies }(i) \text { or }(i i), \\
M(x, 2(\alpha-4) t) & \text { if } \varphi \text { satisfies (iii) }\end{cases}
\end{aligned}
$$

for all $x \in X$ and $t>0$, where

$$
\begin{aligned}
& M(x, t) \\
& \quad:=\min \left\{N^{\prime \prime}(\varphi(x, x, 0,0), t), N^{\prime \prime}(\varphi(-x,-x, 0,0), t)\right\} .
\end{aligned}
$$

Moreover, if $N^{\prime \prime}(\varphi(x, y, 0,0), t)$ is continuous in $x, y$ under the condition (ii), then the mapping $f$ is a quadratic-additive mapping. 
Proof. We will take into account three different cases for the assumption of $\varphi$.

Case 1. Assume that $\varphi$ satisfies the condition (i). We consider the set of functions

$$
S:=\{g: X \longrightarrow Y \mid g(0)=0\}
$$

and introduce a generalized metric on $S$ by

$$
\begin{aligned}
d(g, h):=\inf \{u & \in \mathbb{R}^{+} \mid N^{\prime}(g(x)-h(x), u t) \\
& \geq M(x, t) \forall x \in X\} .
\end{aligned}
$$

We first prove that $d$ is a generalized metric on $S$. If $d(g, h)=0$, that is,

$$
\inf \left\{u \in \mathbb{R}^{+} \mid N^{\prime}(g(x)-h(x), u t) \geq M(x, t) \forall x \in X\right\}
$$$$
=0 \text {, }
$$

then we see that

$$
N^{\prime}(g(x)-h(x), u t) \geq M(x, t)
$$

for all $x \in X$ and all $u>0$, which means that

$$
N^{\prime}(g(x)-h(x), t) \geq M\left(x, \frac{t}{u}\right)
$$

for all $x \in X$ and all $u>0$. It follows that

$$
N^{\prime}(g(x)-h(x), t) \geq \lim _{u \rightarrow 0} M\left(x, \frac{t}{u}\right)=1 .
$$

So we get $g(x)=h(x)$ for all $x \in X$.

Conversely, if $g(x)=h(x)$ for all $x \in X$, then we have

$$
N^{\prime}(g(x)-h(x), u t)=N^{\prime}(0, u t)=1 \geq M(x, t)
$$

for all $u$ and $t$. So we know that

$$
\begin{gathered}
d(g, h)=\inf \left\{u \in \mathbb{R}^{+} \mid N^{\prime}(g(x)-h(x), u t)\right. \\
\geq M(x, t) \quad \forall x \in X\}=0 .
\end{gathered}
$$

Of course, it is easily checked that $d(g, h)=d(h, g)$ for all $g, h \in S$.

Let $u, v>0$ such that $d(f, g)<u$ and $d(g, h)<v$. Then

$$
\begin{gathered}
N^{\prime}(f(x)-g(x), u t) \geq M(x, t), \\
N^{\prime}(g(x)-h(x), v t) \geq M(x, t)
\end{gathered}
$$

for all $x \in X$ and all $t>0$. Thus we find that

$$
\begin{aligned}
& N^{\prime}(f(x)-h(x),(u+v) t) \\
& \quad \geq \min \left\{N^{\prime}(f(x)-g(x), u t), N^{\prime}(g(x)-h(x), v t)\right\} \\
& \quad \geq M(x, t) .
\end{aligned}
$$

This implies that $u+v \geq d(f, h)$. Hence we yield that $d(f, h) \leq$ $d(f, g)+d(g, h)$. Therefore $d$ is a generalized metric on $S$.

Now if we define a function $J: S \rightarrow S$ by

$$
J f(x):=\left(\frac{1}{8}\right)(f(2 x)+f(-2 x))+\left(\frac{1}{4}\right)(f(2 x)-f(-2 x))
$$

for all $x \in X$, then we have

$$
\begin{aligned}
J^{n} f(x)= & 2^{-2 n-1}\left(f\left(2^{n} x\right)+f\left(-2^{n} x\right)\right) \\
& +2^{-n-1}\left(f\left(2^{n} x\right)-f\left(-2^{n} x\right)\right)
\end{aligned}
$$

for all $x \in X$ and all $n \in \mathbb{N} \cup\{0\}$.

For any $f, g \in S$, let $u \in[0, \infty]$ be an arbitrary constant with $d(g, f) \leq u$. The definition of $d$ provides that, for $0<$ $\alpha<2$,

$$
\begin{aligned}
N^{\prime}\left(J g(x)-J f(x), \frac{\alpha u t}{2}\right) & N^{\prime}\left(\left(\frac{3}{8}\right)(g(2 x)-f(2 x))\right. \\
& \left.-\left(\frac{1}{8}\right)(g(-2 x)-f(-2 x)), \frac{\alpha u t}{2}\right) \\
\geq \min \left\{N^{\prime}\left(\left(\frac{3}{8}\right)(g(2 x)-f(2 x)), \frac{3 \alpha u t}{8}\right),\right. & \left.N^{\prime}\left(\left(\frac{1}{8}\right)(g(-2 x)-f(-2 x)), \frac{\alpha u t}{8}\right)\right\} \\
= & \min \left\{N^{\prime}(g(2 x)-f(2 x), \alpha u t),\right. \\
\geq & \min \{M(2 x, \alpha t), M(-2 x, \alpha t)\} \\
\geq & M(x, t)
\end{aligned}
$$

for all $x \in X$, which implies that $d(J f, J g) \leq(\alpha / 2) d(f, g)$. Thus $J$ is a strictly contractive self-mapping of $S$ with the Lipschitz constant $\alpha / 2$.

Moreover, by (4), we see that

$$
\begin{aligned}
& N^{\prime}\left(f(x)-J f(x), \frac{t}{4}\right) \\
& =N^{\prime}\left(\frac{-5 D f(x, x, 0,0)+3 D f(-x,-x, 0,0)}{32}, \frac{t}{4}\right) \\
& \geq \min \left\{N^{\prime}\left(\frac{-5 D f(x, x, 0,0)}{32}, \frac{5 t}{32}\right),\right. \\
& \geq \min \left\{N^{\prime}(D f(x, x, 0,0), t),\right. \\
& \left.N^{\prime}\left(\frac{3 D f(-x,-x, 0,0)}{32}, \frac{3 t}{32}\right)\right\} \\
&
\end{aligned}
$$




$$
\begin{aligned}
& \geq \min \left\{N^{\prime \prime}(\varphi(x, x, 0,0), t),\right. \\
& \left.\quad N^{\prime \prime}(\varphi(-x,-x, 0,0), t)\right\} \\
& =M(x, t)
\end{aligned}
$$

for all $x \in X$. The above inequality and the definition of $d$ show that $d(f, J f) \leq 1 / 4$.

According to Theorem 1 , the sequence $\left\{J^{n} f\right\}$ converges to a unique fixed point $F: X \rightarrow Y$ of $J$ in the set $T=\{g \in S \mid$ $d(f, g)<\infty$, which is represented by

$$
\begin{aligned}
F(x):=N^{\prime}-\lim _{n \rightarrow \infty}( & 2^{-2 n-1}\left(f\left(2^{n} x\right)+f\left(-2^{n} x\right)\right) \\
& \left.+2^{-n-1}\left(f\left(2^{n} x\right)-f\left(-2^{n} x\right)\right)\right)
\end{aligned}
$$

for all $x \in X$. We observe that

$$
d(f, F) \leq \frac{1}{1-\alpha / 2} d(f, J f) \leq \frac{1}{2(2-\alpha)} .
$$

This guarantees that inequality (5) holds.

Next, we are in the position to prove that $F$ is quadraticadditive mapping. Now, we figure out the relation

$$
\begin{aligned}
& N^{\prime}(D F(x, y, z, w), t) \\
& \geq \min \left\{N^{\prime}\left(2\left(F-J^{n} f\right)(x+y+z+w), \frac{t}{30}\right),\right. \\
& N^{\prime}\left(\left(F-J^{n} f\right)(x-y+z+w), \frac{t}{30}\right), \\
& N^{\prime}\left(\left(F-J^{n} f\right)(x+y-z+w), \frac{t}{30}\right), \\
& N^{\prime}\left(\left(F-J^{n} f\right)(x+y+z-w), \frac{t}{30}\right), \\
& N^{\prime}\left(\left(F-J^{n} f\right)(x-y-z+w), \frac{t}{30}\right), \\
& N^{\prime}\left(\left(F-J^{n} f\right)(x-y+z-w), \frac{t}{30}\right), \\
& N^{\prime}\left(\left(F-J^{n} f\right)(x+y-z-w), \frac{t}{30}\right), \\
& N^{\prime}\left(5\left(J^{n} f-F\right)(x), \frac{t}{30}\right), \\
& N^{\prime}\left(3\left(J^{n} f-F\right)(-x), \frac{t}{30}\right), \\
& N^{\prime}\left(5\left(J^{n} f-F\right)(y), \frac{t}{30}\right), \\
& N^{\prime}\left(3\left(J^{n} f-F\right)(-y), \frac{t}{30}\right), \\
& N^{\prime}\left(5\left(J^{n} f-F\right)(z), \frac{t}{30}\right) \text {, } \\
& N^{\prime}\left(3\left(J^{n} f-F\right)(-z), \frac{t}{30}\right),
\end{aligned}
$$

$$
\begin{aligned}
& N^{\prime}\left(5\left(J^{n} f-F\right)(w), \frac{t}{30}\right), \\
& N^{\prime}\left(3\left(J^{n} f-F\right)(-w), \frac{t}{30}\right), \\
& \left.N^{\prime}\left(D J^{n} f(x, y, z, w), \frac{t}{2}\right)\right\}
\end{aligned}
$$

for all $x, y, z, w \in X$ and all $n \in \mathbb{N}$. The first fifteen terms on the right-hand side of the above inequality tend to 1 as $n \rightarrow \infty$ by the definition of $F$. Moreover, we find that

$$
\begin{aligned}
N^{\prime}\left(D J^{n} f(x, y, z, w), \frac{t}{2}\right) & \min \left\{N^{\prime}\left(2^{-2 n-1} D f\left(2^{n} x, 2^{n} y, 2^{n} z, 2^{n} w\right), \frac{t}{8}\right),\right. \\
& N^{\prime}\left(2^{-2 n-1} D f\left(-2^{n} x,-2^{n} y,-2^{n} z,-2^{n} w\right), \frac{t}{8}\right), \\
& N^{\prime}\left(2^{-n-1} D f\left(2^{n} x, 2^{n} y, 2^{n} z, 2^{n} w\right), \frac{t}{8}\right), \\
& \left.N^{\prime}\left(2^{-n-1} D f\left(-2^{n} x,-2^{n} y,-2^{n} z,-2^{n} w\right), \frac{t}{8}\right)\right\} \\
& N^{\prime}\left(D f\left(2^{n} x, 2^{n} y, 2^{n} z, 2^{n} w\right), 2^{2 n-2} t\right), \\
& N^{\prime}\left(D f\left(-2^{n} x,-2^{n} y,-2^{n} z,-2^{n} w\right), 2^{2 n-2} t\right), \\
& N^{\prime}\left(D f\left(2^{n} x, 2^{n} y, 2^{n} z, 2^{n} w\right), 2^{n-2} t\right), \\
& \left.N^{\prime}\left(D f\left(-2^{n} x,-2^{n} y,-2^{n} z,-2^{n} w\right), 2^{n-2} t\right)\right\} \\
& N^{\prime \prime}\left(\varphi(x, y, z, w), 2^{n-2} \alpha^{-n} t\right), \\
& N^{\prime \prime}\left(\varphi(x, y, z, w), 2^{2 n-2} \alpha^{-n} t\right),
\end{aligned}
$$

which tends to 1 as $n \rightarrow \infty$, since $2 / \alpha>1$. Therefore inequality (23) gives that

$$
N^{\prime}(D F(x, y, z, w), t)=1
$$

for all $x, y, z, w \in X$ and $t>0$. So we deduce that $D F(x, y, z, w)=0$ for all $x, y, z, w \in X$.

In order to show the uniqueness of $F$, we assume that $F^{\prime}$ : $X \rightarrow Y$ is another quadratic-additive mapping satisfying (5), and then we yield that

$$
\begin{aligned}
J F^{\prime}(x) & =\frac{5 D F^{\prime}(x, x, 0,0)-3 D F^{\prime}(-x,-x, 0,0)}{32}+F^{\prime}(x) \\
& =F^{\prime}(x)
\end{aligned}
$$


for all $x \in X$. That is, $F^{\prime}$ is another fixed point of $J$. Since $F$ is a unique fixed point of $J$ in the set $T$, we conclude that $F=F^{\prime}$.

Case 2. Assume that $\varphi$ satisfies the condition (ii). The proof of this case can be carried out similarly as the proof of Case 1 . In particular, assume that $N^{\prime \prime}(\varphi(x, y, 0,0), t)$ is continuous in $x, y$. If $M, a, b, c, d$ are any fixed nonzero integers, then we have

$$
\begin{aligned}
& \lim _{n \rightarrow \infty} N^{\prime \prime}\left(\varphi\left(\left(2^{n} a+b\right) x,\left(2^{n} c+d\right) y, 0,0\right), t\right) \\
& \quad \geq \lim _{n \rightarrow \infty} N^{\prime \prime}\left(\varphi\left(\left(a+2^{-n} b\right) x,\left(c+2^{-n} d\right) y, 0,0\right), \alpha^{-n} t\right) \\
& \quad \geq \lim _{n \rightarrow \infty} N^{\prime \prime}\left(\varphi\left(\left(a+2^{-n} b\right) x,\left(c+2^{-n} d\right) y, 0,0\right), M t\right) \\
& \quad=N^{\prime \prime}(\varphi(a x, c y, 0,0), M t)
\end{aligned}
$$

for all $x, y \in X$ and $t>0$. Since $n$ is arbitrary, we have

$$
\begin{gathered}
\lim _{n \rightarrow \infty} N^{\prime \prime}\left(\varphi\left(\left(2^{n} a+b\right) x,\left(2^{n} c+d\right) y, 0,0\right), t\right) \\
\geq \lim _{M \rightarrow \infty} N^{\prime \prime}(\varphi(a x, c y, 0,0), M t)=1
\end{gathered}
$$

for all $x, y, z, w \in X$ and $t>0$. From these and the following equality:

$$
\begin{aligned}
(F-f)(x)= & \frac{3}{8}(D F-D f)\left(\left(2^{n}+1\right) x,-2^{n} x, 0,0\right) \\
& -\frac{1}{8}(D F-D f)\left(-\left(2^{n}+1\right) x, 2^{n} x, 0,0\right) \\
& -\frac{1}{2}(F-f)\left(\left(2^{n+1}+1\right) x\right) \\
& -\frac{1}{2}(F-f)\left(-\left(2^{n+1}+1\right) x\right) \\
& +\frac{3}{2}(F-f)\left(\left(2^{n}+1\right) x\right) \\
& +\frac{1}{2}(F-f)\left(-\left(2^{n}+1\right) x\right) \\
& +\frac{3}{2}(F-f)\left(2^{n} x\right)+\frac{1}{2}(F-f)\left(2^{n} x\right),
\end{aligned}
$$

we get the inequality

$$
\begin{aligned}
N^{\prime}\left((F-f)(x), \frac{11 t}{2}\right) & \\
\geq \lim _{n \rightarrow \infty} \min \{ & N^{\prime \prime}\left(\frac{3}{8} \varphi\left(\left(2^{n}+1\right) x,-2^{n} x, 0,0\right), \frac{3 t}{8}\right), \\
& N^{\prime \prime}\left(\frac{1}{8} \varphi\left(-\left(2^{n}+1\right) x, 2^{n} x, 0,0\right), \frac{t}{8}\right), \\
& M\left(\left(2^{n+1}+1\right) x, 2(2-\alpha) t\right), \\
& M\left(\left(2^{n}+1\right) x, 2(2-\alpha) t\right), \\
& \left.M\left(2^{n} x, 2(2-\alpha) t\right)\right\}=1
\end{aligned}
$$

for all $x \in X$. Due to the previous inequality and the fact that $f(0)=0=F(0)$, we obtain that $f \equiv F$.

Case 3. Assume that $\varphi$ satisfies the condition (iii). Let the set $(S, d)$ be as in the proof of Case 1. Now we take into account the function $J: S \rightarrow S$ defined by

$$
J g(x):=g\left(\frac{x}{2}\right)-g\left(-\frac{x}{2}\right)+2\left(g\left(\frac{x}{2}\right)+g\left(-\frac{x}{2}\right)\right)
$$

for all $g \in S$ and $x \in X$. Note that

$$
\begin{aligned}
J^{n} g(x)= & 2^{n-1}\left(g\left(2^{-n} x\right)-g\left(-2^{-n} x\right)\right) \\
& +2^{2 n-1}\left(g\left(2^{-n} x\right)+g\left(-2^{-n} x\right)\right)
\end{aligned}
$$

and $J^{0} g(x)=g(x)$ for all $x \in X$. Let $f, g \in S$ and let $u \in$ $[0, \infty]$ be an arbitrary constant with $d(g, f) \leq u$. From the definition of $d$, we have

$$
\begin{aligned}
& N^{\prime}\left(J g(x)-J f(x), \frac{4 u t}{\alpha}\right) \\
& =N^{\prime}\left(3\left(g\left(\frac{x}{2}\right)-f\left(\frac{x}{2}\right)\right)\right. \\
& \left.+\left(g\left(-\frac{x}{2}\right)-f\left(-\frac{x}{2}\right)\right), \frac{4 u t}{\alpha}\right) \\
& \geq \min \left\{N^{\prime}\left(3\left(g\left(\frac{x}{2}\right)-f\left(\frac{x}{2}\right)\right), \frac{3 u t}{\alpha}\right),\right. \\
& \left.\quad N^{\prime}\left(g\left(-\frac{x}{2}\right)-f\left(-\frac{x}{2}\right), \frac{u t}{\alpha}\right)\right\} \\
& \geq \min \left\{N^{\prime}\left(g\left(\frac{x}{2}\right)-f\left(\frac{x}{2}\right), \frac{u t}{\alpha}\right),\right. \\
& \left.\quad N^{\prime}\left(g\left(-\frac{x}{2}\right)-f\left(-\frac{x}{2}\right), \frac{u t}{\alpha}\right)\right\} \\
& =M(x, t)
\end{aligned}
$$

for all $x \in X$, which means that $d(J f, J g) \leq(4 / \alpha) d(f, g)$. Hence $J$ is a strictly contractive self-mapping of $S$ with the Lipschitz constant $0<4 / \alpha<1$.

Moreover, by (4), we see that

$$
\begin{aligned}
& N^{\prime}\left(f(x)-J f(x), \frac{t}{2 \alpha}\right) \\
& =N^{\prime}\left(\frac{3 D f(x / 2, x / 2,0,0)}{8}\right. \\
& \left.\quad-\frac{D f(-x / 2,-x / 2,0,0)}{8}, \frac{t}{2 \alpha}\right) \\
& \geq \min \left\{N^{\prime \prime}\left(3 \varphi\left(\frac{x}{2}, \frac{x}{2,0,0}\right), \frac{3 t}{\alpha}\right),\right. \\
& \left.N^{\prime \prime}\left(\varphi\left(-\frac{x}{2},-\frac{x}{2,0,0}\right), \frac{t}{\alpha}\right)\right\} \\
& \geq M(x, t)
\end{aligned}
$$


for all $x \in X$. It implies that $d(f, J f) \leq 1 / 2 \alpha$ by the definition of $d$. Therefore, according to Theorem 1 , the sequence $\left\{J^{n} f\right\}$ converges to a unique fixed point $F: X \rightarrow Y$ of $J$ in the set $T=\{g \in S \mid d(f, g)<\infty\}$, which is represented by

$$
\begin{aligned}
F(x)=N^{\prime}-\lim _{n \rightarrow \infty} & \left(2^{n-1}\left(f\left(2^{-n} x\right)-f\left(-2^{-n} x\right)\right)\right. \\
+2^{2 n-1}( & \left.\left.f\left(2^{-n} x\right)+f\left(-2^{-n} x\right)\right)\right)
\end{aligned}
$$

for all $x \in X$. Since

$$
d(f, F) \leq \frac{1}{1-4 / \alpha} d(f, J f) \leq \frac{1}{2(\alpha-4)},
$$

inequality (5) holds.

Next, we will show that $F$ is quadratic-additive mapping. As in the previous case, we have inequality (23) for all $x, y, z, w \in X$ and all $n \in \mathbb{N}$. The first terms on the right-hand side of inequality (23) tend to 1 as $n \rightarrow \infty$ by the definition of $F$. Now consider that

$$
\begin{aligned}
N^{\prime}\left(D J^{n} f(x, y, z, w), \frac{t}{2}\right) \\
\geq \min \left\{N^{\prime}\left(2^{2 n-1} D f\left(2^{-n} x, 2^{-n} y, 2^{-n} z, 2^{-n} w\right), \frac{t}{8}\right),\right. \\
N^{\prime}\left(2^{2 n-1} D f\left(-2^{-n} x,-2^{-n} y,-2^{-n} z,-2^{-n} w\right) \frac{t}{8}\right), \\
N^{\prime}\left(2^{n-1} D f\left(2^{-n} x, 2^{-n} y, 2^{-n} z, 2^{-n} w\right), \frac{t}{8}\right), \\
N^{\prime}\left(-2^{n-1} D f\left(-2^{-n} x,-2^{-n} y,-2^{-n} z,-2^{-n} w\right),\right. \\
\geq \min \left\{N^{\prime \prime}\left(\varphi(x, y, z, w), 2^{-2 n-2} \alpha^{n} t\right),\right. \\
N^{\prime \prime}\left(\varphi(-x,-y,-z,-w), 2^{-2 n-2} \alpha^{n} t\right), \\
N^{\prime \prime}\left(\varphi(x, y, z, w), 2^{-n-2} \alpha^{n} t\right), \\
\left.N^{\prime \prime}\left(\varphi(-x,-y,-z,-w), 2^{-n-2} \alpha^{n} t\right)\right\},
\end{aligned}
$$

which tends to 1 as $n \rightarrow \infty$ for all $x, y, z, w \in X$. Therefore it follows from (23) that

$$
N^{\prime}(D F(x, y, z, w), t)=1
$$

for all $x, y, z, w \in X$ and $t>0$. That is, $D F(x, y, z, w)=0$ for all $x, y, z, w \in X$.

In particular, instead of the assumption of Theorem 3 that $(X, N)$ is a fuzzy normed space, it is enough to consider that $X$ is a linear space. Moreover, we can use Theorem 3 to get a classical result in the framework of normed spaces. Let $(X,\|\cdot\|)$ be a normed linear space. Then we can define a fuzzy norm $N_{X}$ on $X$ by following

$$
N_{X}(x, t)= \begin{cases}0, & t \leq\|x\|, \\ 1, & t>\|x\|,\end{cases}
$$

where $x \in X$ and $t \in \mathbb{R}$, and see [12].
Theorem 4. Let $X$ and $Y$ be a normed space and a complete normed space, respectively. If a mapping $f: X \rightarrow Y$ satisfies

$$
\|D f(x, y, z, w)\| \leq\|x\|^{p}+\|y\|^{p}+\|z\|^{p}+\|w\|^{p}
$$

for all $x, y, z, w \in X$ and a fixed $p \in(0,1) \cup(2, \infty)$, then there exists a unique quadratic-additive mapping $F: X \rightarrow Y$ such that

$$
\|f(x)-F(x)\| \leq \begin{cases}\frac{\|x\|^{p}}{2-2^{p}} & \text { if } 0<p<1, \\ \frac{\|x\|^{p}}{2^{p}-4} & \text { if } p>2\end{cases}
$$

for all $x \in X$.

Proof. Let $N_{Y}$ be a fuzzy norm on $Y$. Then we get

$$
N_{Y}(D f(x, y, z, w), t)= \begin{cases}0 & \text { if } t \leq\|D f(x, y, z, w)\| \|, \\ 1 & \text { if } t>\|D f(x, y, z, w)\| \|\end{cases}
$$

for all $x, y, z, w \in X$ and all $t \in \mathbb{R}$ and

$$
\begin{aligned}
N_{\mathbb{R}} & \left(\|x\|^{p}+\|y\|^{p}+\|z\|^{p}+\|w\|^{p}, t\right) \\
& = \begin{cases}0 & \text { if } t \leq\|x\|^{p}+\|y\|^{p}+\|z\|^{p}+\|w\|^{p}, \\
1 & \text { if } t>\|x\|^{p}+\|y\|^{p}+\|z\|^{p}+\|w\|^{p}\end{cases}
\end{aligned}
$$

for all $x, y, z, w \in X$ and all $t \in \mathbb{R}$. Therefore, it follows from (40) that

$$
\begin{aligned}
& N_{Y}(D f(x, y, z, w), t) \\
& \quad \geq N_{\mathbb{R}}\left(\|x\|^{p}+\|y\|^{p}+\|z\|^{p}+\|w\|^{p}, t\right) .
\end{aligned}
$$

If we define a mapping $\varphi: X^{4} \rightarrow \mathbb{R}$ by

$$
\varphi(x, y, z, w):=\|x\|^{p}+\|y\|^{p}+\|z\|^{p}+\|w\|^{p},
$$

then we see that $f$ and $\varphi$ satisfy the conditions of Theorem 3 with $\alpha=\alpha^{\prime}=2^{p}$ for $0<p<1$ and $\alpha=2^{p}$ for $p>2$. So we feel that (41) holds for all $x \in X$.

Theorem 5. Let $X$ and $Y$ be a normed space and a complete normed space, respectively. Assume that $\phi: X \rightarrow \mathbb{R}$ is a mapping defined by

$$
\phi(x)= \begin{cases}\|x\|^{p} & \text { if } x \neq 0, \\ 0 & \text { if } x=0\end{cases}
$$

for all $x \in X$ and a fixed $p<0$. Suppose that $f: X \rightarrow Y$ is a mapping such that

$$
\|D f(x, y, z, w)\| \leq \phi(x)+\phi(y)+\phi(z)+\phi(w)
$$

for all $x, y, z, w \in X$. Then the mapping $f$ is a quadraticadditive mapping.

Proof. If we define a mapping $\varphi: X^{4} \rightarrow \mathbb{R}$ by

$$
\varphi(x, y, z, w):=\phi(x)+\phi(y)+\phi(z)+\phi(w),
$$

then $f$ and $\varphi$ are fulfilled in the conditions of Theorem 3 with $\alpha<2^{p}<1$. Based on the fact that $N_{\mathbb{R}}(\varphi(x, y, 0,0), t)$ is continuous in $x, y$ under the condition (ii), we arrive at the desired conclusion. 


\section{Conflict of Interests}

The authors declare that there is no conflict of interests regarding the publication of this paper.

\section{Acknowledgments}

The authors would like to thank the referees for giving useful suggestions and for the improvement of this paper. The first author was supported by the Basic Science Research Program through the National Research Foundation of Korea (NRF) funded by the Ministry of Education (no. 2013R1A1A2A10004419).

\section{References}

[1] S. M. Ulam, A Collection of Mathematical Problems, Interscience, New York, NY, USA, 1960.

[2] D. H. Hyers, "On the stability of the linear functional equation," Proceedings of the National Academy of Sciences of the United States of America, vol. 27, pp. 222-224, 1941.

[3] T. Aoki, "On the stability of the linear transformation in Banach spaces," Journal of the Mathematical Society of Japan, vol. 2, pp. 64-66, 1950.

[4] T. M. Rassias, "On the stability of the linear mapping in Banach spaces," Proceedings of the American Mathematical Society, vol. 72, no. 2, pp. 297-300, 1978.

[5] L. Cădariu and V. Radu, "Fixed points and the stability of Jensen's functional equation," Journal of Inequalities in Pure and Applied Mathematics, vol. 4, no. 1, article 4, 2003.

[6] L. Cǎdariu and V. Radu, "Fixed points and the stability of quadratic functional equations," Analele Universităţii de Vest din Timişoara. Seria Matematică-Informatică, vol. 41, no. 1, pp. 2548, 2003.

[7] L. Cădariu and V. Radu, "On the stability of the Cauchy functional equation: a fixed point approach," Grazer Mathematische Berichte, vol. 346, pp. 43-52, 2004.

[8] A. K. Katsaras, "Fuzzy topological vector spaces II," Fuzzy Sets and Systems, vol. 12, no. 2, pp. 143-154, 1984.

[9] T. Bag and S. K. Samanta, "Finite dimensional fuzzy normed linear spaces," Journal of Fuzzy Mathematics, vol. 11, no. 3, pp. 687-705, 2003.

[10] S. C. Cheng and J. N. Mordeson, "Fuzzy linear operators and fuzzy normed linear spaces," Bulletin of the Calcutta Mathematical Society, vol. 86, no. 5, pp. 429-436, 1994.

[11] I. Kramosil and J. Michálek, "Fuzzy metrics and statistical metric spaces," Kybernetika, vol. 11, no. 5, pp. 336-344, 1975.

[12] A. K. Mirmostafaee and M. S. Moslehian, "Fuzzy almost quadratic functions," Results in Mathematics, vol. 52, no. 1-2, pp. 161-177, 2008.

[13] A. K. Mirmostafaee and M. S. Moslehian, "Fuzzy versions of Hyers-Ulam-Rassias theorem," Fuzzy Sets and Systems, vol. 159, no. 6, pp. 720-729, 2008.

[14] L. Cădariu and V. Radu, "Fixed points and generalized stability for functional equations in abstract spaces," Journal of Mathematical Inequalities, vol. 3, no. 3, pp. 463-473, 2009.

[15] L. Cădariu and V. Radu, "Fixed points and stability for functional equations in probabilistic metric and random normed spaces," Fixed Point Theory and Applications, vol. 2009, Article ID 589143, 2009.
[16] D. Miheț, "The probabilistic stability for a functional equation in a single variable," Acta Mathematica Hungarica, vol. 123, no. 3, pp. 249-256, 2009.

[17] D. Miheț and V. Radu, "On the stability of the additive Cauchy functional equation in random normed spaces," Journal of Mathematical Analysis and Applications, vol. 343, no. 1, pp. 567572, 2008.

[18] D. Miheț, "The fixed point method for fuzzy stability of the Jensen functional equation," Fuzzy Sets and Systems, vol. 160, no. 11, pp. 1663-1667, 2009.

[19] D. Miheț, "The stability of the additive Cauchy functional equation in non-Archimedean fuzzy normed spaces," Fuzzy Sets and Systems, vol. 161, no. 16, pp. 2206-2212, 2010.

[20] A. K. Mirmostafaee, M. Mirzavaziri, and M. S. Moslehian, "Fuzzy stability of the Jensen functional equation," Fuzzy Sets and Systems, vol. 159, no. 6, pp. 730-738, 2008.

[21] A. K. Mirmostafaee and M. S. Moslehian, "Stability of additive mappings in non-Archimedean fuzzy normed spaces," Fuzzy Sets and Systems, vol. 160, no. 11, pp. 1643-1652, 2009.

[22] Y.-H. Lee, "On the quadratic additive type functional equations," International Journal of Mathematical Analysis, vol. 7, no. 37-40, pp. 1935-1948, 2013.

[23] J. B. Diaz and B. Margolis, "A fixed point theorem of the alternative, for contractions on a generalized complete metric space," Bulletin of the American Mathematical Society, vol. 74, pp. 305-309, 1968.

[24] I. A. Rus, Principles and Applications of Fixed Point Theory, 1979, C.-N. Dacia, Eds., 1979 (Romanian).

[25] D. Miheț and C. Zaharia, "Probabilistic (quasi)metric versions for a stability result of Baker," Abstract and Applied Analysis, vol. 2012, Article ID 269701, 10 pages, 2012. 


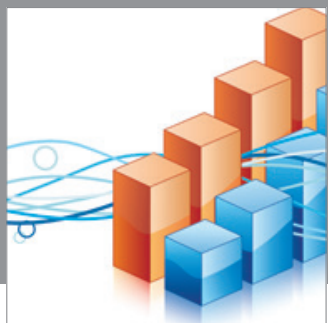

Advances in

Operations Research

mansans

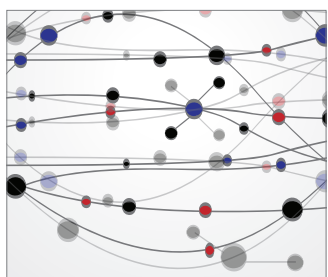

The Scientific World Journal
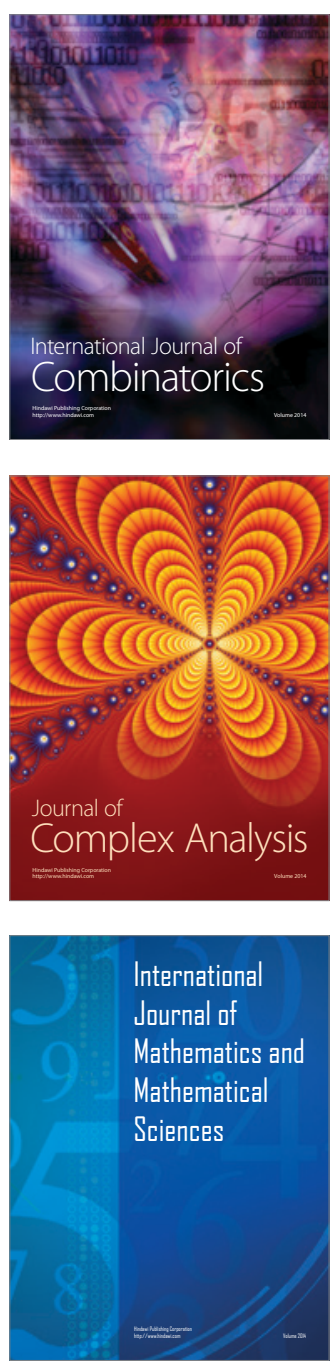
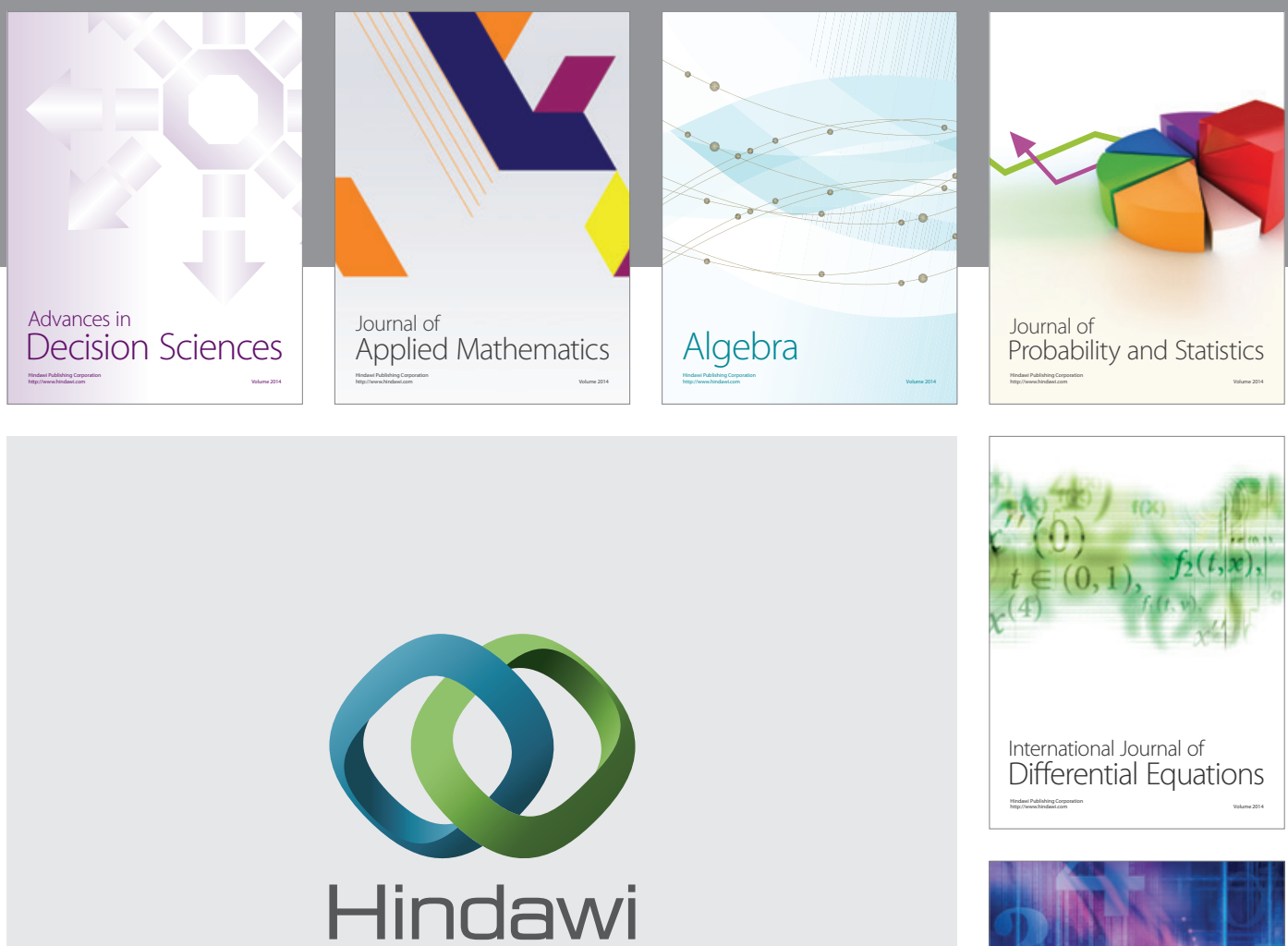

Submit your manuscripts at http://www.hindawi.com
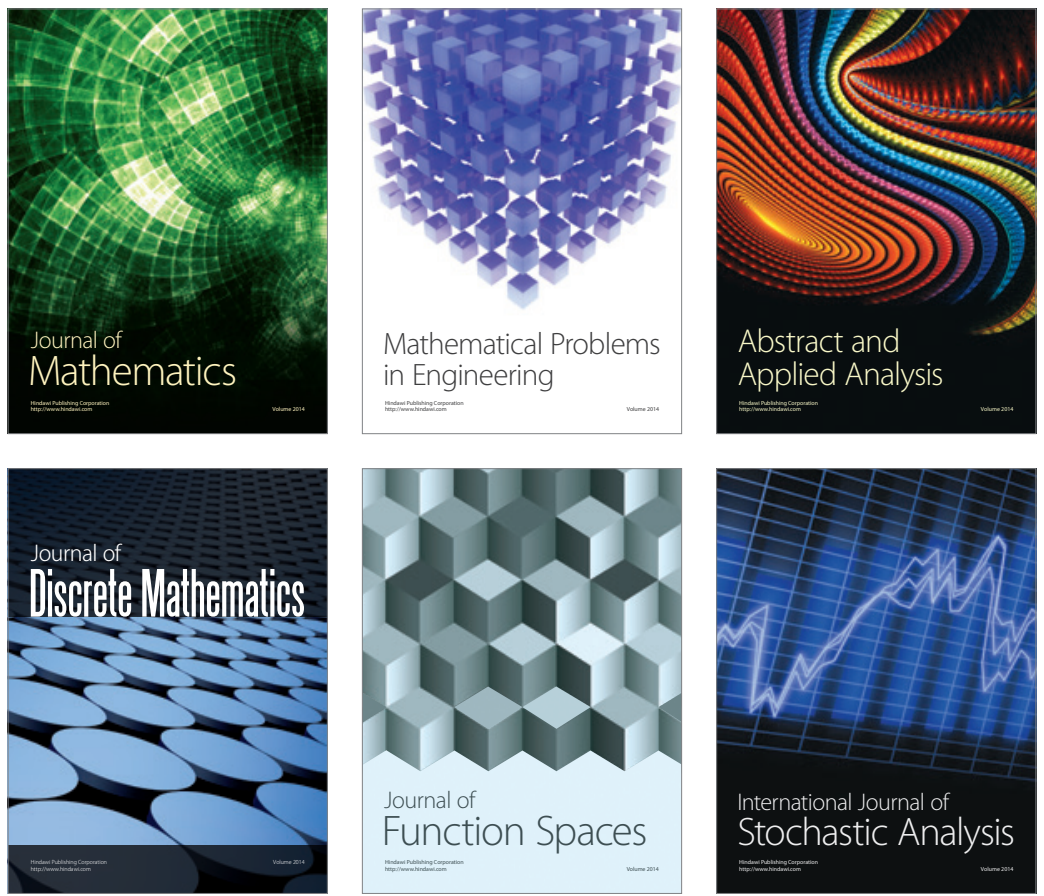

Journal of

Function Spaces

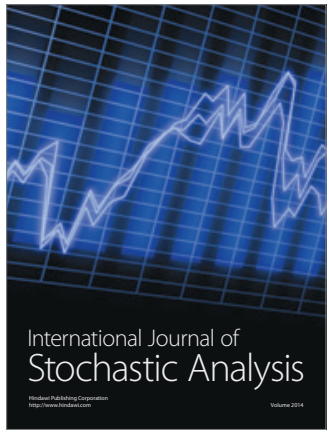

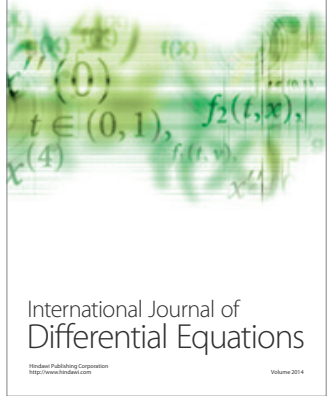
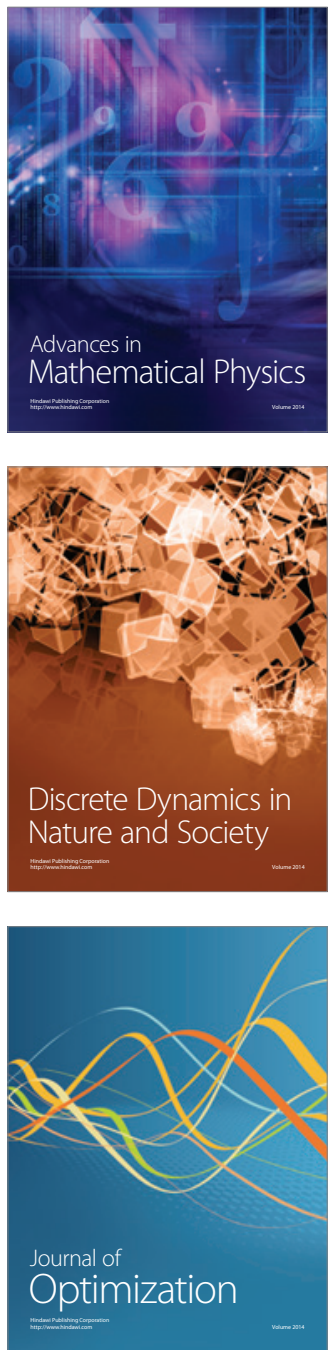